\title{
Reconstructing, Monitoring, and Predicting Multidecadal-Scale Changes in the North Atlantic Thermohaline Circulation with Sea Surface Temperature
}

\author{
M. LATIF \\ Institut für Meereskunde, Kiel, Germany
}

\author{
E. Roeckner, M. Botzet, M. Esch, H. HaAk, S. Hagemann, J. Jungclaus, S. Legutke, \\ S. Marsland, AND U. MikolajewiCZ \\ Max-Planck-Institut für Meteorologie, Hamburg, Germany
}

\section{J. MitCHELL}

Met Office, Hadley Centre for Climate Prediction and Research, Bracknell, Berkshire, United Kingdom

26 November 2002 and 17 October 2003

\section{ABSTRACT}

\begin{abstract}
Sea surface temperature (SST) observations in the North Atlantic indicate the existence of strong multidecadal variability with a unique spatial structure. It is shown by means of a new global climate model, which does not employ flux adjustments, that the multidecadal SST variability is closely related to variations in the North Atlantic thermohaline circulation (THC). The close correspondence between the North Atlantic SST and THC variabilities allows, in conjunction with the dynamical inertia of the THC, for the prediction of the slowly varying component of the North Atlantic climate system. It is shown additionally that past variations of the North Atlantic THC can be reconstructed from a simple North Atlantic SST index and that future, anthropogenically forced changes in the THC can be easily monitored by observing SSTs. The latter is confirmed by another state-ofthe-art global climate model. Finally, the strong multidecadal variability may mask an anthropogenic signal in the North Atlantic for some decades.
\end{abstract}

\section{Introduction}

The North Atlantic thermohaline circulation is an important component of the global climate system. Strong and rapid changes in the thermohaline circulation (THC) have been reported from paleoclimatic records (e.g., Broecker et al. 1985), and it is currently discussed whether greenhouse warming may have a serious impact on the stability of the THC (e.g., Cubasch et al. 2001). The North Atlantic SST varied on a wide range of time scales during the last century (e.g., Deser and Blackmon 1993). It has been pointed out by Bjerknes (1964) that the short-term interannual variations are driven primarily by the atmosphere, while the long-term multidecadal changes may be forced by variations in ocean dynamics. The latter is supported by simulations with coupled ocean-atmosphere models (Delworth et al. 1993; Tim-

Corresponding author address: Dr. M. Latif, Institut für Meereskunde, Düsternbrooker Weg 20, D-24105 Kiel, Germany.

E-mail: mlatif@ifm.uni-kiel.de mermann et al. 1998), which show that variations in the North Atlantic THC reflect themselves in large-scale SST anomalies. Recently, consistency between the observed multidecadal SST variability derived from paleoclimatic and instrumental data and that simulated by two versions of the Geophysical Fluid Dynamics Laboratory (GFDL) coupled model has been demonstrated (Delworth and Mann 2000).

Changes in the THC strength may have strong implications for global and regional climates (e.g., Manabe and Stouffer 1999). Low-frequency changes of the THC may arise from internal interactions between the ocean and the atmosphere (e.g., Latif 1998) and/or in response to external forcing, such as global warming (e.g., Rahmstorf 1999). However, up to the present, there exists no means to observe the variability of the THC. Here, we present a method to reconstruct past variations of the THC and to monitor and predict the state of the North Atlantic climate system in the future by simply observing Atlantic SSTs. A large body of literature exists on the SST variability of the Atlantic. The existence 


\section{North Atlantic SST anomalies}

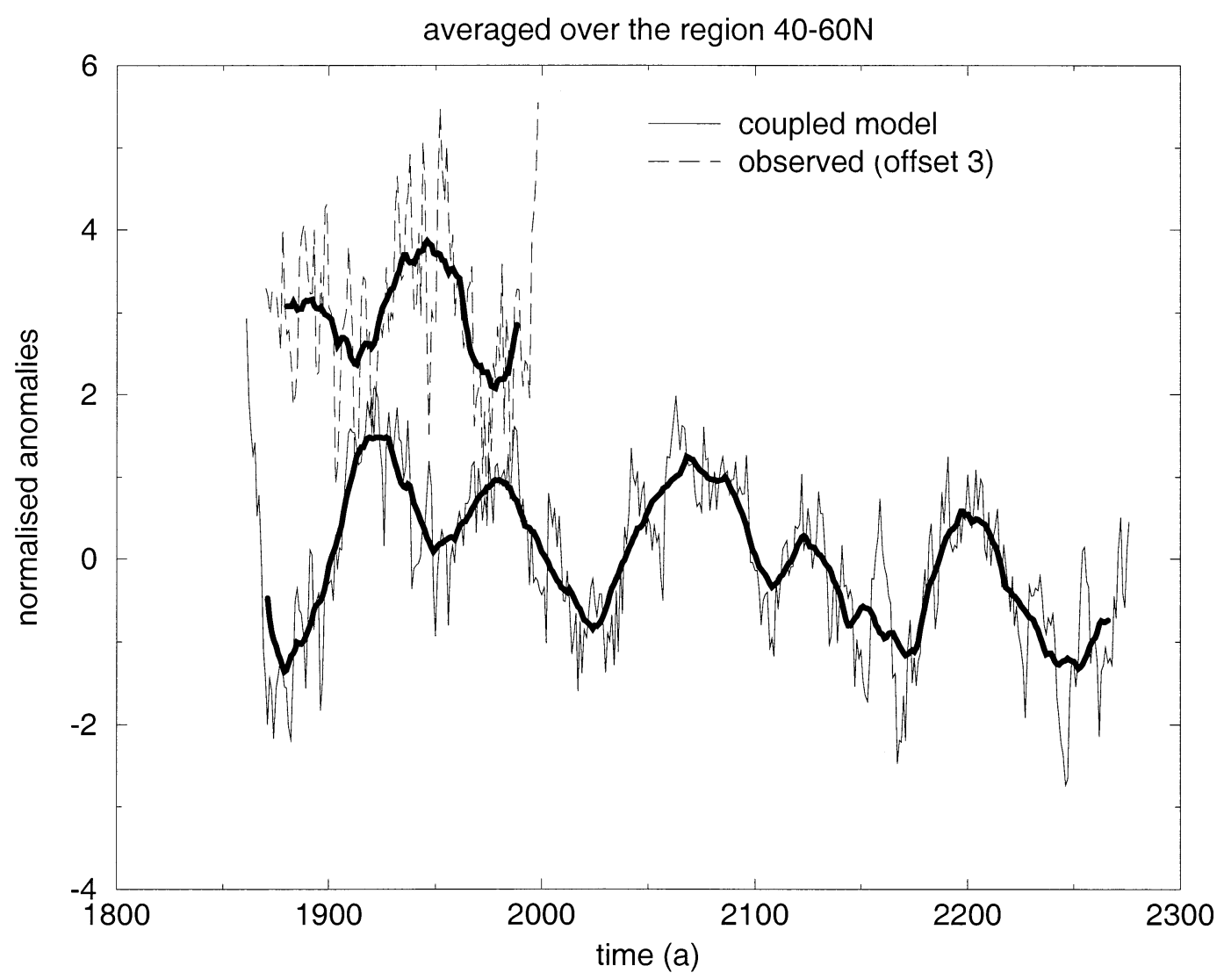

FIG. 1. Time series of the observed annual North Atlantic SST anomalies averaged over the region $40^{\circ}-60^{\circ} \mathrm{N}$ and $50^{\circ}-10^{\circ} \mathrm{W}$ (dashed thin line) and the corresponding model time series (full thin line). The thick curves are the corresponding 21-yr running means, which highlight the multidecadal variability. The time series were normalized with their respective standard deviations and the observed time series has an offset of three for better comparion with the model time series. The standard deviation of the observed index amounts to $0.3^{\circ} \mathrm{C}$ and that of the model index to $0.6^{\circ} \mathrm{C}$.

of multidecadal SST variability with opposite signs in the North and South Atlantic and its impact on Sahelian rainfall was described by Folland et al. (1984, 1986). The multidecadal SST variability in the Atlantic Ocean has also been described in many subsequent papers (e.g., Delworth and Mann 2000 and references therein). The inference, however, that the THC variability can be readily obtained from observing SSTs has not been drawn so far. Here, we present results from two global climate models that demonstrate the close connection between THC strength and Atlantic SST. Our work can be viewed as a straightforward extension of the work conducted with simple box models (e.g., Stommel 1961; Marotzke and Stone 1995; Griffies and Tziperman 1995), in which the temperature of the northern box reflects THC variability.

\section{Multidecadal SST variability}

We analyze first the latest Hadley Centre SST dataset, which covers the period 1870-1998. This dataset is part- ly described in Folland et al. (1999). The monthly values were averaged to annual mean values, which is justified, because we concentrate here on the multidecadal time scale. Coupled model simulations with and without ocean dynamics (not shown) indicate that one of the regions of strong influence of the ocean dynamics on SST is the North Atlantic between $40^{\circ}$ and $60^{\circ} \mathrm{N}$. We, therefore, define an SST index that averages the SST over the region $40^{\circ}-60^{\circ} \mathrm{N}$ and $50^{\circ}-10^{\circ} \mathrm{W}$. This index shows some rather strong multidecadal variability (Fig. 1), with anomalously high SSTs around 1900 and the 1950s, and increasing SSTs during the most recent years. Also shown is the low-pass-filtered version of the North Atlantic SST index, using a 21-yr running mean filter. It is noted that the SST index does not correspond well to the North Atlantic Oscillation (NAO) index (see e.g., Hurrell 1995), a measure of the westerlies over the North Atlantic, which suggests that the North Atlantic SST variability is not simply a response to the low-frequency variations in the NAO. As will be shown below by 
(a) corr. of SST with multi-decadal mode, obs.

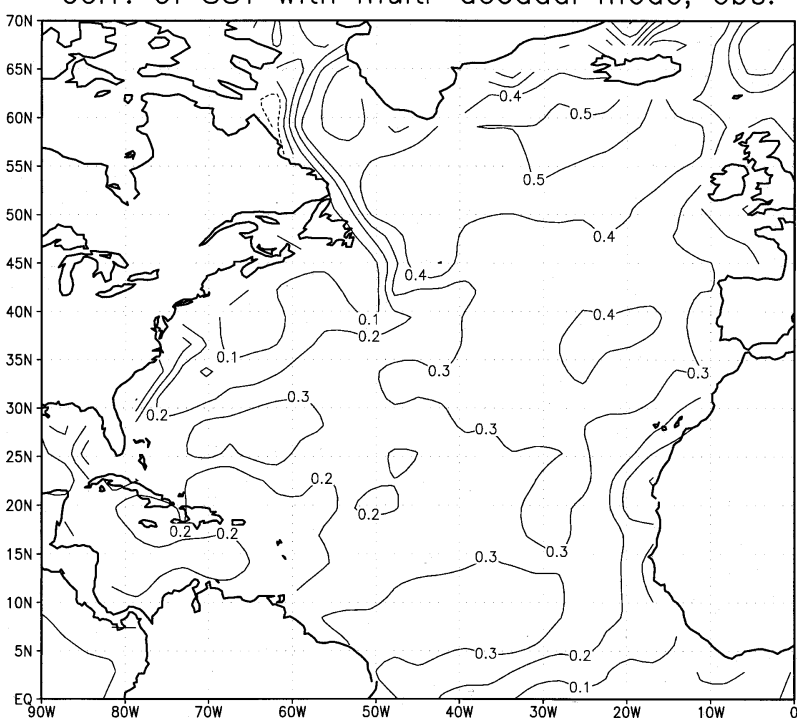

(b)

corr. of SST with multi-decadal mode, model

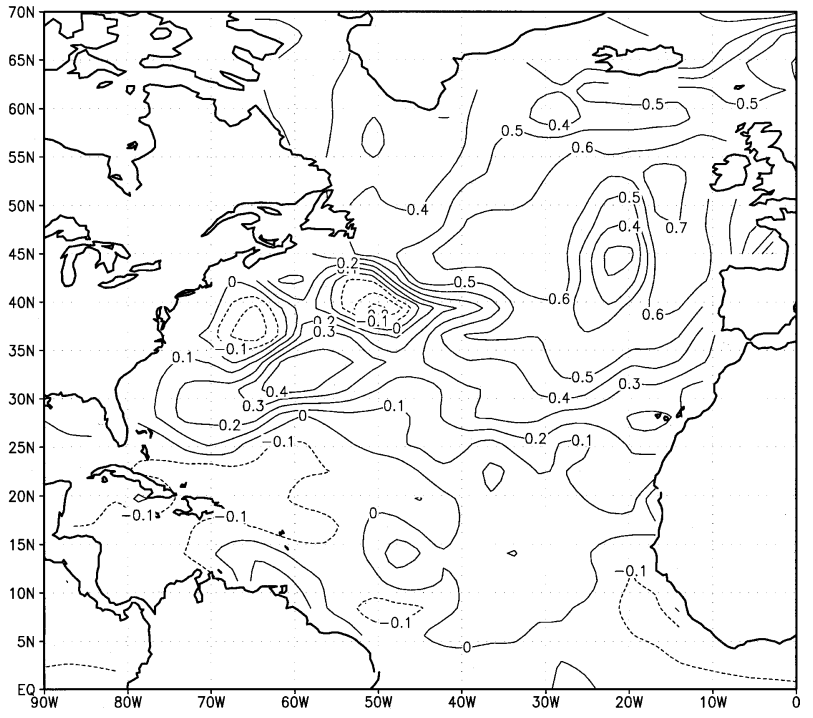

FIG. 2. (a) Map of correlations of the observed annual SST anomalies in the North Atlantic with the low-pass-filtered observed North Atlantic SST index shown in Fig. 1. (b) Map of correlations of the simulated annual SST anomalies in the North Atlantic with the simulated low-pass-filtered North Atlantic SST index shown in Fig. 1.

discussing model results, the type of multidecadal variability considered here originates in the ocean. Furthermore, we would like to point out that the North Atlantic SST index does not exhibit any strong trend during the last several decades, but shows instead a rather oscillatory behavior throughout the analyzed period.

We computed the spatial anomaly structure of North Atlantic SST that goes along with the multidecadal variability (Fig. 2a). It is rather homogeneous and was discussed, for instance, by Folland et al. $(1984,1986)$ and
Delworth and Mann (2000). Anomalies of the same sign cover basically the whole North Atlantic Ocean from the equator to the high latitudes, with the strongest values near $60^{\circ} \mathrm{N}$. Anomalies of the opposite sign are found in the South Atlantic (not shown). This SST anomaly pattern, associated with the multidecadal variability, is strikingly different to the characteristic SST anomaly pattern associated with the higher-frequency interannual variability. The latter is characterized by the well-known North Atlantic tripolar SST anomaly pattern (Visbeck et al. 1998), which is forced by the atmosphere through surface heat flux anomalies associated with the NAO. Thus, the multidecadal SST variability in the North Atlantic exhibits a unique spatial structure. In order to investigate the dynamics of the multidecadal SST variability further, we analyze next the results from an extended-range integration with our global climate model.

The model used in this study to explore the dynamics of the multidecadal SST variability is the new MaxPlanck-Institute for Meteorology (MPI) global climate model. The ocean component MPI-OM1 (Marsland et al. 2003) is based on a C-grid version of the Hamburg Ocean Model in Primitive Equations (HOPE) ocean model and employs variable horizontal resolution, with relatively high resolution $(\sim 10-50 \mathrm{~km})$ in the high latitudes and near the equator. The atmosphere model is ECHAM5, the latest cycle of the ECHAM (European Centre Hamburg) atmosphere model. It is run at T42 resolution, which corresponds to a horizontal resolution of about $2.8^{\circ} \times 2.8^{\circ}$. A high vertical resolution version of ECHAM5 has been used by Giorgetta et al. (2002) to study the dynamics of the stratospheric quasi-biennial oscillation (QBO). A Hibler-type dynamic-thermodynamic sea ice model and a river runoff scheme are included in the climate model. Glacier calving is treated in a simple but interactive manner. The climate model does not employ flux adjustments or any other corrections. Here, a 400-yr-long control integration with the model is analyzed. The model simulates the present-day climate of the North Atlantic realistically. The climate model's thermohaline circulation is consistent with observations, with a maximum overturning of about $20 \mathrm{~Sv}$ ( $1 \mathrm{~Sv} \equiv 10^{6} \mathrm{~m}^{3} \mathrm{~s}^{-1}$ ) and a northward heat transport of about $0.8 \mathrm{PW}$ at $30^{\circ} \mathrm{N}$ (Marsland et al. 2003).

The model simulates the tripolar SST anomaly pattern in the North Atlantic at interannual time scales, and, consistent with observations, it is forced by the NAO (not shown). The model also simulates pronounced multidecadal variability in North Atlantic SST. The same North Atlantic SST index that was computed from the observations was derived from the model simulation (Fig. 1). The time series demonstrates that after some initial rapid adjustment, the model oscillates with a multidecadal time scale similar to that observed. However, the SST fluctuations simulated by the model are larger than those observed. The standard deviation of the model index is about twice as large as that derived from the observed index. In order to highlight the multidecadal 


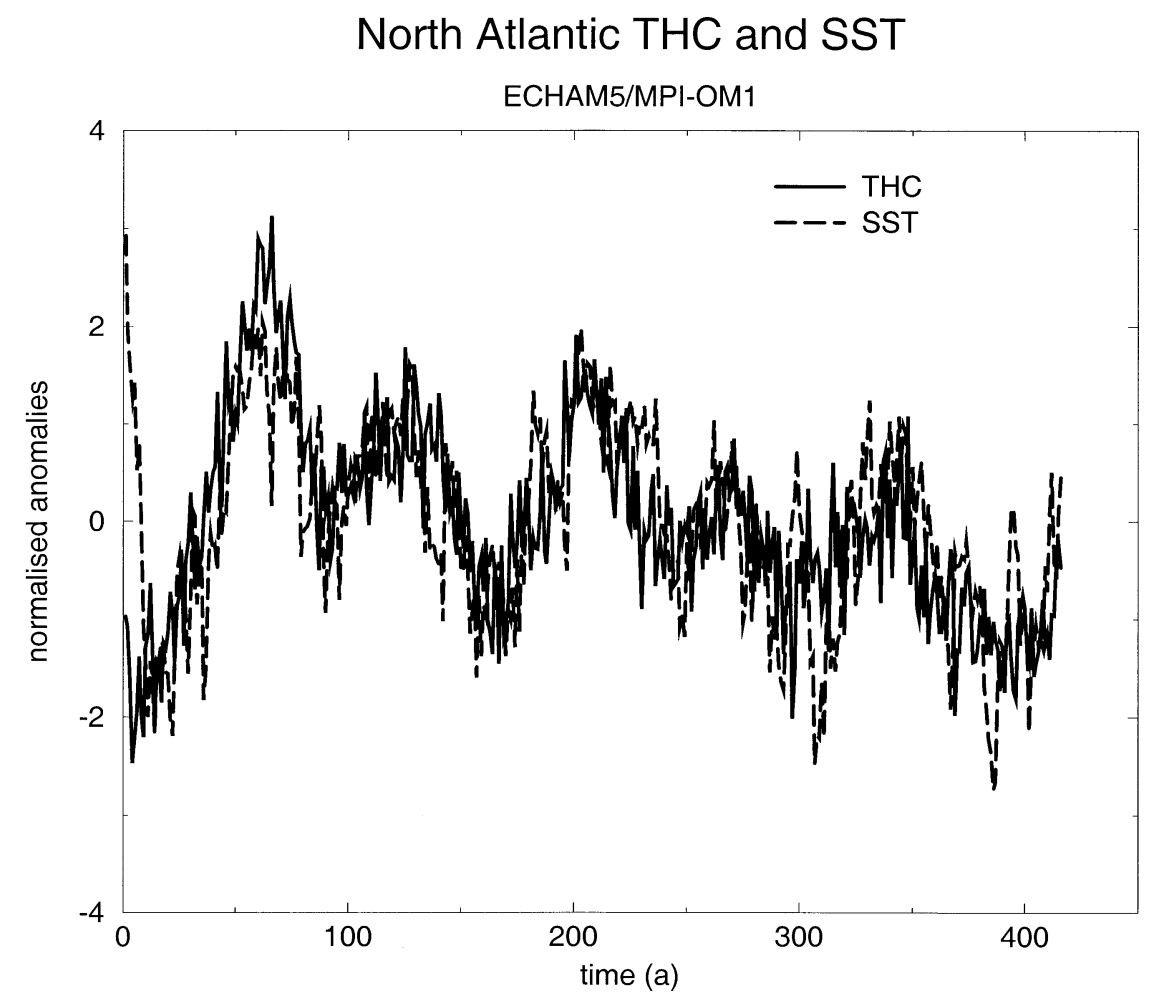

FIG. 3. Time series of simulated annual mean North Atlantic SST anomalies $\left(40^{\circ}-60^{\circ} \mathrm{N}\right.$ and $50^{\circ}-10^{\circ} \mathrm{W}$, dashed line) and annual mean anomalies of the maximum overturning at $30^{\circ} \mathrm{N}$ (full line), a measure of the strength of the model's thermohaline circulation. Note that both time series are highly correlated at time scales beyond several years, indicating that the low-frequency variations of the THC can be monitored by SSTs. Both time series were normalized with their respective standard deviations. The standard deviation of the SST index amounts to $0.6^{\circ} \mathrm{C}$ and that of the THC index to $1.9 \mathrm{~Sv}$.

variability, the 21-yr running mean is also shown for the model simulation. Next, we computed the SST pattern associated with the multidecadal variability of the model (Fig. 2b). The model SST anomaly pattern, associated with the multidecadal variability, is consistent with that derived from the observations and also is characterized by a rather homogeneous pattern in the North Atlantic. The associated atmospheric surface pressure pattern in the model resembles the East Atlantic Pattern (EAP, not shown). Correlations of the SST index with surface air temperature and precipitation over the adjacent land areas are generally weak and only marginally significant in a few regions, such as western Europe. A more detailed description of the signature of the multidecadal SST fluctuations over land areas will be given in a forthcoming paper (Pohlmann et al. 2004, manuscript submitted to J. Climate). Consistent with the observational finding, the NAO index is not significantly correlated to the multidecadal SST variations in the model. Some small regional differences exist between the observed and simulated SST patterns. The correlation maximum is simulated farther south, and the minimum at $40^{\circ} \mathrm{N}$ in the western Atlantic is somewhat deeper in the model. Nevertheless, we conclude that our climate model simulates realistically the multidecadal variability in the North Atlantic, so that it can be used to study the origin of the SST variability.

\section{Origin of the multidecadal SST variability}

The climate model offers us the possibility to investigate the physics behind the multidecadal SST changes. An investigation of the model's thermohaline circulation and North Atlantic SST revealed that both are closely related to each other (Fig. 3). Specifically, the strength of the meridional overturning at $30^{\circ} \mathrm{N}$ correlates almost perfectly with the North Atlantic SST index, defined above at time scales beyond several years. The correlation of the two time series amounts to about 0.7 , with the THC index leading the SST index by a few years. This suggests that the multidecadal SST fluctuations are driven by ocean dynamics, which is also supported by the investigation of the surface heat flux anomalies averaged over the same region as the SST. The heat flux anomalies are strongly anticorrelated with the SST anomalies, which is demonstrated by the cross-correlation function between North Atlantic SST and surface heat flux anomalies (Fig. 4a), which exhibits the stron- 
(a)

cross correlation between SST and surface heat flux

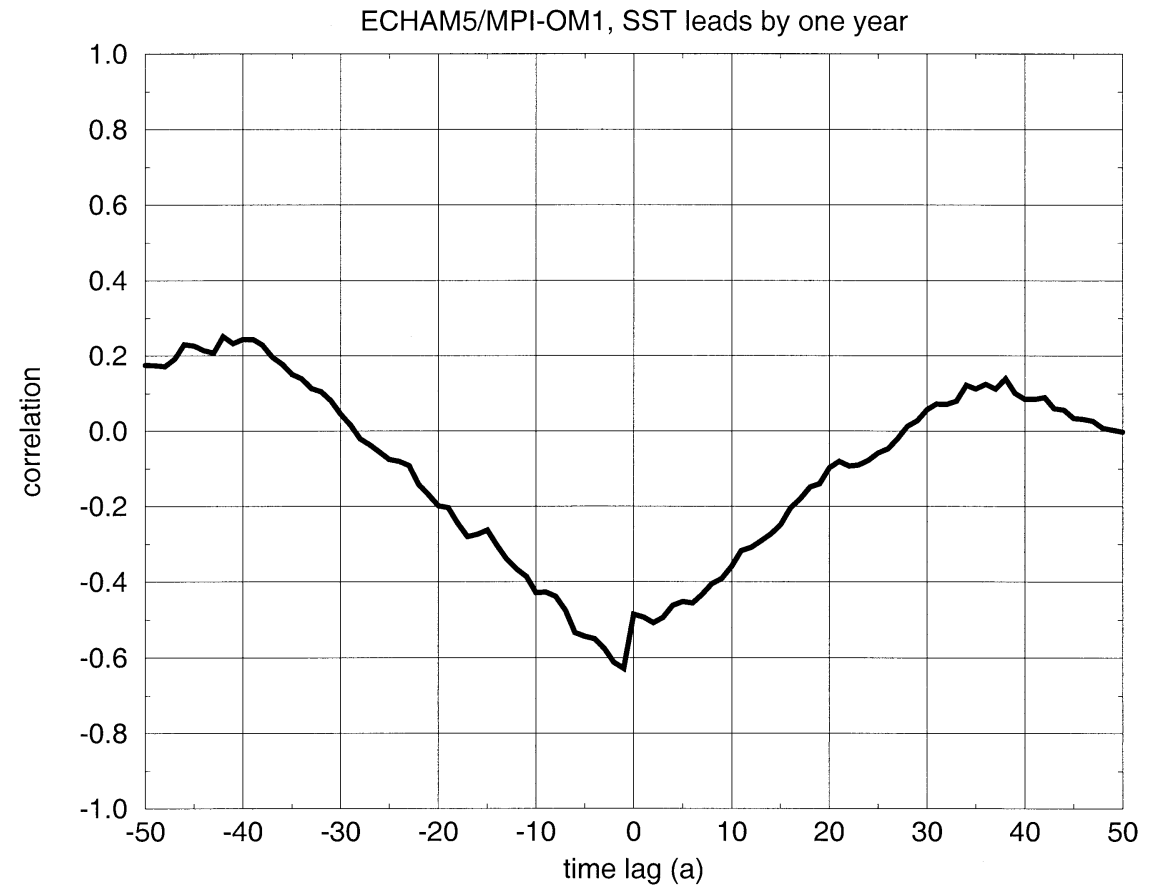

(b)

\section{cross correlation between SST and ocean heat transport}

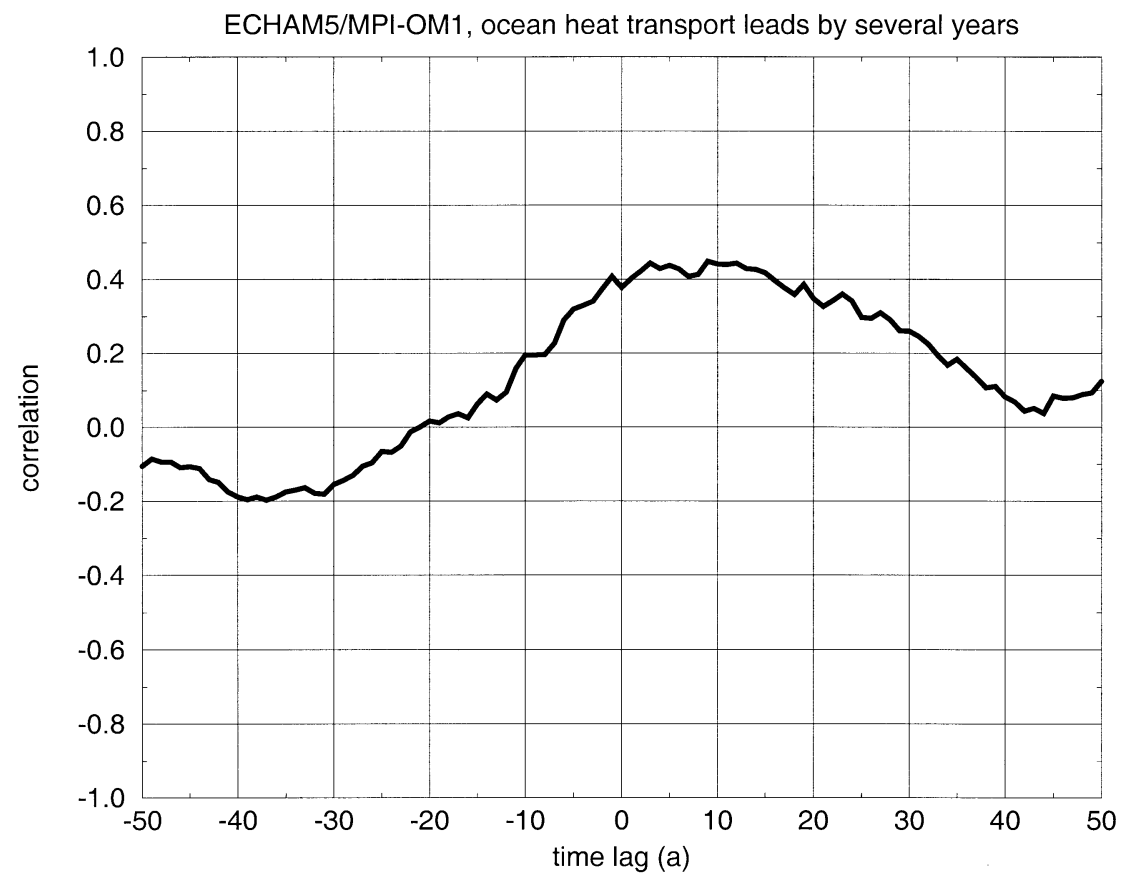

FIG. 4. (a) Cross correlation of the North Atlantic SST anomalies (shown in Fig. 1) and the net surface heat flux anomalies averaged over the same region as function of the time lag (year). Please note that the SST and the heat flux are negatively correlated, so that the heat flux can be regarded as a damping for the SST anomalies. (b) Cross correlation of the North Atlantic SST index with the northward ocean heat transport at $30^{\circ} \mathrm{N}$ as function of the time lag (year). Maximum correlation is found at positive time lags, which indicates that the ocean heat transport leads the SST. This demonstrates, together with the upper panel, that it is the ocean dynamics that drive the SST. 
(a) control vs. $1 \%$ integrations

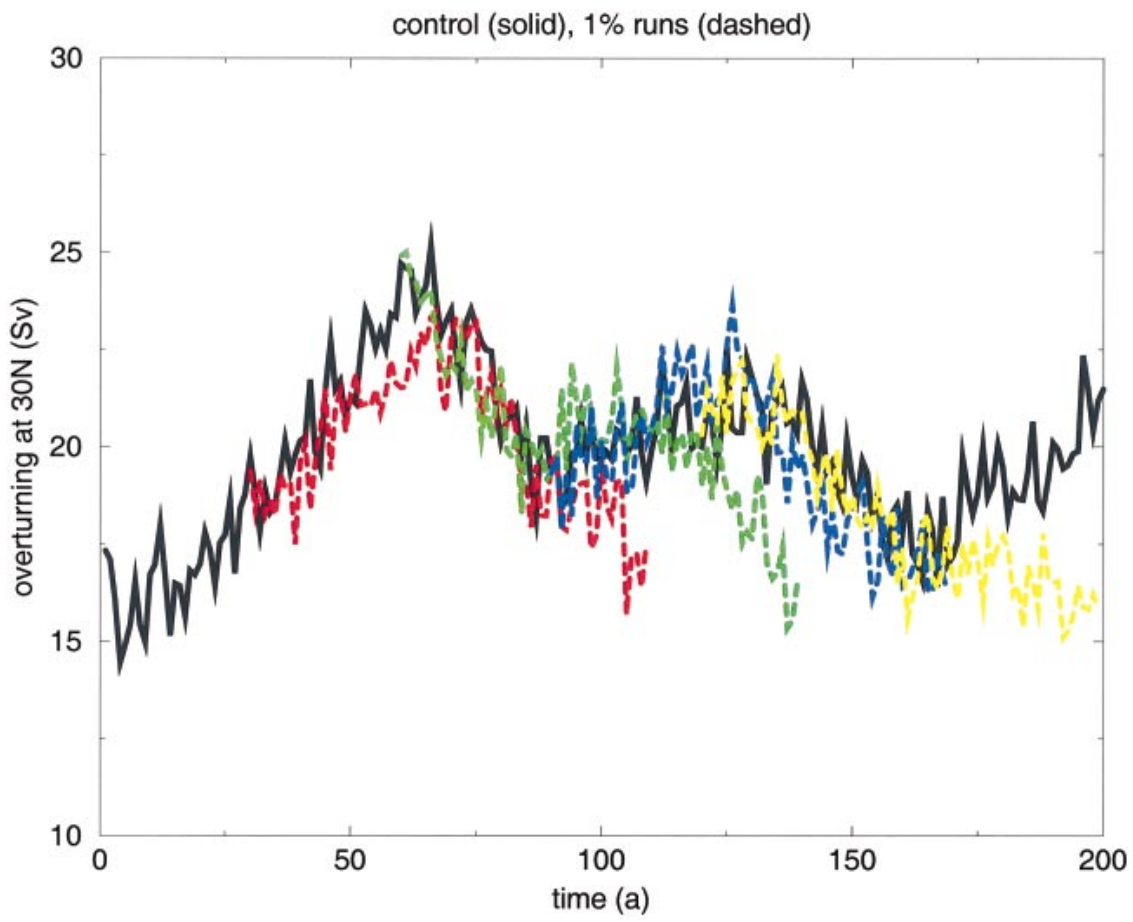

FIG. 5. (a) Time series of the annual mean anomalies of the maximum overturning ( $\mathrm{Sv}$ ) at $30^{\circ} \mathrm{N}$ in the control integration (black line) and in the greenhouse warming simulations (colored lines). Note that the evolutions in the greenhouse warming simulations closely follow those of the control integration for several decades, indicating a very high level of THC predictability.

gest negative correlations near zero lag. Thus, the surface heat flux can be regarded as a damping for the SST anomalies - a result that is also supported by observations (WOCE 2001). Some additional observational evidence for such a relationship has been provided by Bjerknes (1964) and by Kushnir (1994), but it should be noted that the data quality is not sufficient to explore the SST-heat flux relationship in greater detail.

A clear connection of the SST anomalies is found to the northward oceanic heat transport at $30^{\circ} \mathrm{N}$. The ocean heat transport leads the North Atlantic SST by several years, as shown by the cross correlation between the meridional ocean heat transport and the SST anomalies (Fig. 4b). The heat transport has a thermohaline and a wind-driven part. We investigated the relative roles of the two components of the ocean heat transport for the SST variability. To evaluate the response of the ocean gyre circulation to wind stress variations, we used the Sverdrup relation and assumed a narrow return flow at the western boundary (Visbeck et al. 2003). The Sverdrup transport is given by $M_{\mathrm{SV}}=\int(\operatorname{curl} \tau) /(\rho \beta) d x$, where the integral is taken over the ocean interior, excluding the western boundary current region, which is respresented by the two grid points nearest to the western boundary. Therefore, the heat flux contribution due to changes in the gyre circulation is given by $Q_{\mathrm{Sv}}=c_{p} / \beta$ $\int\left\{\left[T_{i}(x)-T_{\mathrm{wb}}\right] \operatorname{curl} \tau\right\} d x$, where $T_{i}$ is the upper-ocean temperature in the interior and $T_{\mathrm{wb}}$ is the temperature in the western boundary current region. We found by applying cross-spectral analyses that the wind-driven part of the heat transport is only relevant for the SST variability at shorter time scales of several years and that, on the multidecadal time scale, it is the thermohaline part that dominates. Our results are also consistent with modeling studies investigating the stability of the THC (e.g., Manabe and Stouffer 1988; Schiller et al. 1997). In particular, the SST response to a shutdown of the THC shows large similarities to the SST anomaly pattern discussed above.

The close connection between THC strength and SST variability can be used to either reconstruct changes in the THC from observations or to monitor the state of the THC in the future. If our model mimics the real relationship between THC and SST correctly, the observed multidecadal changes in North Atlantic SST (Fig. 1) can be interpreted as changes in the THC strength: decade-long positive anomalies in the North Atlantic SST index can be regarded as indicators for an anomalously strong THC, and vice versa. In particular, the strong cooling during the period 1960-90 may just as well be related to an anomalously weak THC as part of an internal oscillation than to anthropogenic factors, as hypothesized by some authors (e.g., Hegerl et al. 1997), because the cooling is replaced by a warming during 


\section{(b) North Atlantic THC and dipole SST index}

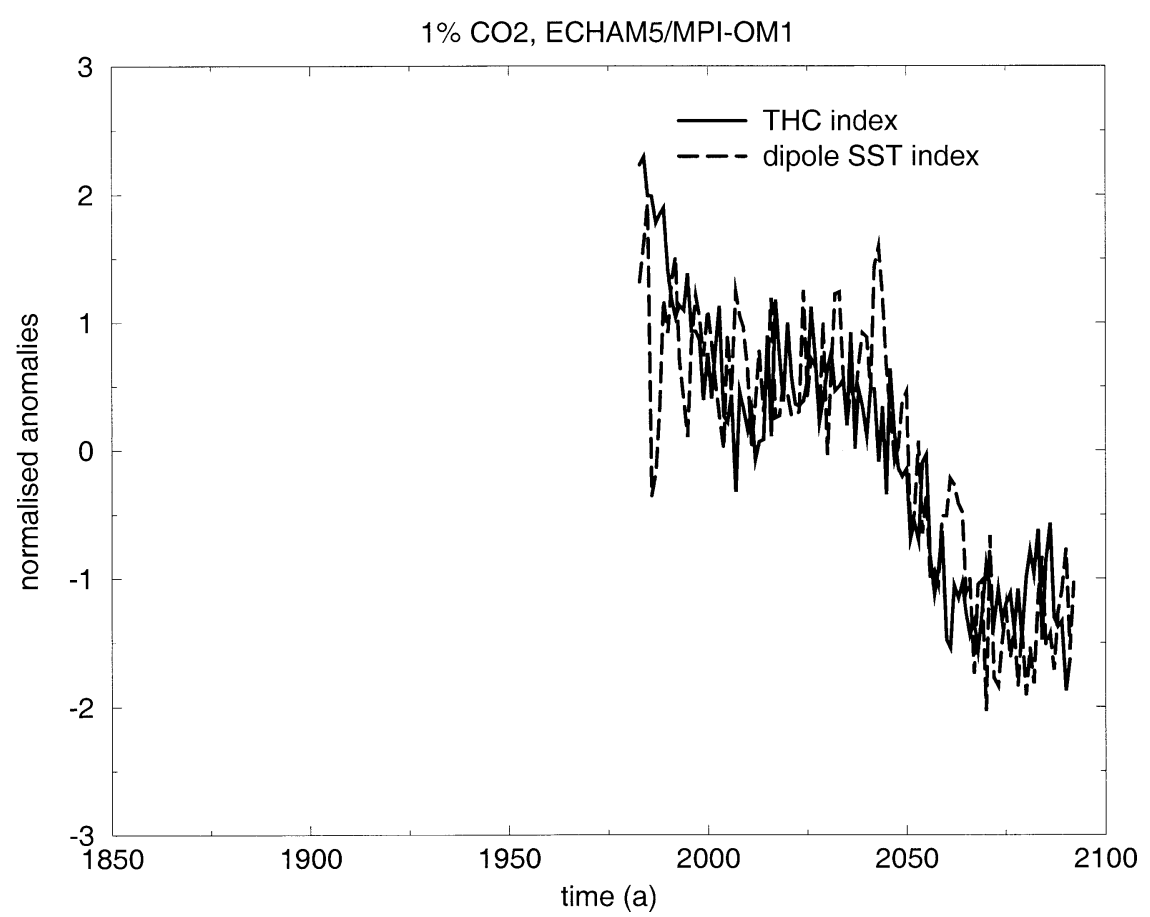

FIG. 5. (b) Time series of the simulated annual mean Atlantic dipole SST index (dashed line) and annual mean anomalies of the maximum overturning at $30^{\circ} \mathrm{N}$ (full line) in the longest of the greenhouse warming simulations. The dipole SST index is defined as the difference between North Atlantic $\left(40^{\circ}-60^{\circ} \mathrm{N}\right.$ and $\left.50^{\circ}-10^{\circ} \mathrm{W}\right)$ and South Atlantic $\left(10^{\circ}-40^{\circ} \mathrm{S}\right.$ and $\left.30^{\circ} \mathrm{W}-10^{\circ} \mathrm{E}\right) \mathrm{SST}$. The time has been adjusted to ease comparison with panel (c).

the most recent years. This is also supported by the Arctic surface air temperature, which shows a midcentury maximum with a peak around 1935. After a cold period in the 1970 s, temperatures have been rising again and have just recently exceeded the warming of the 1940s. This behavior is also known as "low-frequency oscillation," a term coined by Polyakov and Johnson (2000) to describe the intrinsic variability seen in various Northern Hemisphere climate variables, which is apparently related to variations in the Atlantic thermohaline circulation.

\section{Greenhouse warming simulations}

The SST anomaly pattern associated with the THC variability can also be used as a fingerprint to detect future changes in THC intensity. Many authors have reported a weakening of the THC in global warming simulations (see, e.g., Cubasch et al. 2001; Rahmstorf 1999), which may have strong impacts on the climate of the North Atlantic-European sector. However, it is unclear how such a change in THC intensity can be observed. Our model results suggest that an easy means to monitor the THC strength can be obtained simply by observing Atlantic SSTs. However, in the presence of global warming a differential SST index that measures the contrast between the North and South Atlantic has to be used. In order to test this hypothesis, an additional ensemble of four greenhouse warming simulations was conducted (Fig. 5a). For this purpose the climate model was initialized from different states of the control integration that are 30-yr apart from each other (years 30, 60,90 , and 120), and the atmospheric $\mathrm{CO}_{2}$ content was increased by $1 \% \mathrm{yr}^{-1}$ (compound). The results are analyzed for the longest integration $(110 \mathrm{yr}$, initialized in year 60) in which the $\mathrm{CO}_{2}$ concentration triples, and they confirm the hypothesis that changes in THC strength can be seen in the differential Atlantic SST index (Fig. 5b). We note that we used differently defined dipole indices, but the results are insensitive to the choice of the dipole index.

The results also show that the THC evolution in the greenhouse warming simulations closely follows that of the control run for some decades before diverging from it (Fig. 5a). This behavior is markedly different from that of global mean surface temperature, which exhibits a rather monotonic increase in all four realizations (not shown). This implies a strong sensitivity to initial conditions, but also a great deal of predictability of the multidecadal variability in the North Atlantic, provided that the initial state is well known. Furthermore, our results imply that anthropogenically forced changes in 


\section{(c) North Atlantic THC and dipole SST index}

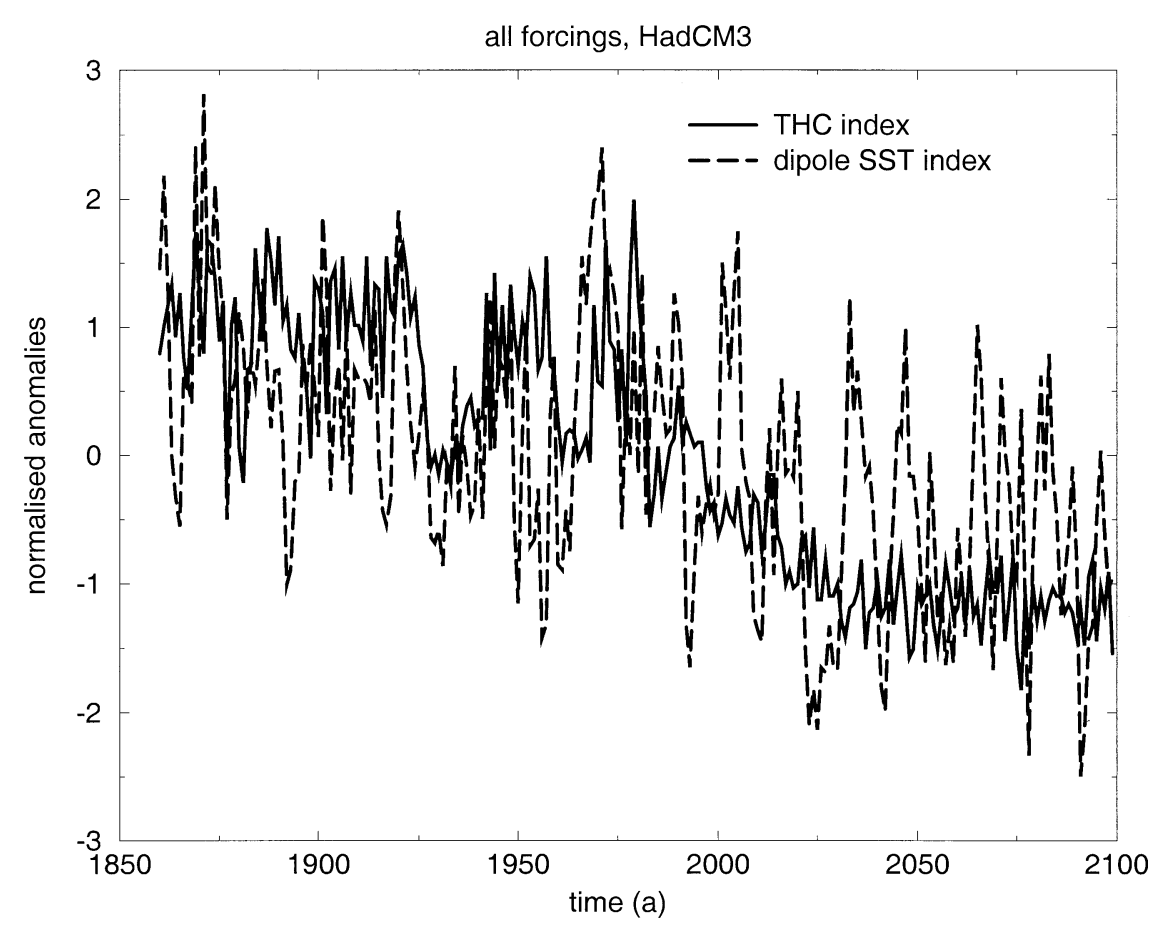

FIG. 5. (c) Results from the Hadley Centre global climate model HadCM3, which was forced by increased levels of greenhouse gases according to IPCC scenario 1992a. Note that in both models SST and overturning are highly correlated at time scales beyond several years in the greenhouse warming simulations. This implies that future changes in the THC can be monitored by observing SSTs. The time series were normalized with their respective standard deviations.

THC strength may be masked for quite a long time by the presence of the internal multidecadal variability. The next several decades may, therefore, be dominated by the internal multidecadal variability, and we have to consider a joint initial/boundary value problem when assessing how the THC will evolve during this century. Greenhouse gas simulations should, therefore, be properly initialized using present-day ocean conditions, and they should be conducted in ensemble mode to assess the uncertainty.

\section{Summary and discussion}

A close relationship exists between multidecadal variations in the strength of the North Atlantic thermohaline circulation and Atlantic sea surface temperature. This has been shown by means of simulations with a global climate model that realistically simulates the multidecadal SST variability in the North Atlantic. The same relationship was found in another climate model (ECHAM4/OPYC, not shown) which was used by Latif et al. (2000), for instance, to discuss the stability of the THC in a greenhouse warming simulation. The link between THC strength and SST can be exploited to reconstruct past and to monitor future changes in the strength of the THC-using SSTs only. Because SSTs are observable from space using passive microwave techniques, they are readily available in near-real time with good spatial and temporal coverage. Thus, the low-frequency variability of a major component of the largescale ocean circulation, the North Atlantic thermohaline circulation, can be determined from the already existing ocean-observing system.

These results are also important in view of the predictability of the North Atlantic climate system at decadal time scales. As shown by analyzing the results of the ensemble of greenhouse warming simulations, the North Atlantic thermohaline circulation exhibits a relatively high degree of predictability at decadal time scales, which is consistent with earlier predictability studies (Griffies and Bryan 1997; Grötzner et al. 1999; Saravanan et al. 2000). We performed additionally an ensemble of classical predictability experiments with our coupled model and found that SST anomalies in the North Atlantic are predictable a few decades ahead. These results will be described in detail in a forthcoming paper. Predictability, however, depends on the availability of the initial state. The relationship between variations in THC and SST found in our climate model can also be exploited for predictability purposes, because the initial oceanic state can be estimated from the history of SST. A simple statistical scheme, for instance, can 
be envisaged to reconstruct the multidecadal variations in the oceanic density structure by projecting the multidecadal SST fluctuations onto the three-dimensional oceanic density field using a model-derived statistical transfer function. These reconstructions can then easily be used in a data-assimilation procedure to produce an ocean analysis from which the decadal predictions can be initialized. If skillful, such predictions of decadal changes in the THC would not only be of enormous scientific but also large public interest, because they would have a large economic value.

One of the main caveats of this study is that it relies heavily on a global climate model. Although the model realistically simulates the North Atlantic thermohaline circulation and its multidecadal variability, it remains to be shown that the mechanisms leading to the model variability are also those operating in reality. However, the lack of a suitable observational database prevents a more detailed verification of the model dynamics. We, therefore, analyzed additionally the results from another global climate model [the Third Hadley Centre Coupled Ocean-Atmosphere General Circulation Model (HadCM3); Gordon et al. 2000]. This model also does not employ flux corrections and its simulation compares well with the observed thermohaline circulation (Wood et al. 1999). The model was forced by increased levels on greenhouse gas concentrations according to the Intergovernmental Panel on Climate Change (IPCC) scenario 1992a. This model simulation confirms our conclusion and shows also a close connection between the low-frequency evolution of the THC index and that of the dipolar SST index in the greenhouse warming simulation (Fig. 5c). The HadCM3 SST simulation, however, is noisier than that of ECHAM5-MPI-OM1 (Fig. $5 b$ ), but the dipolar SST index shows a gradual downward trend during the second half of the greenhouse warming integration as the THC weakens.

However, more model studies on this subject are necessary. Here, we conclude that the potential may exist to reconstruct, monitor, and predict decadal changes in the North Atlantic climate using only surface observations. The situation may be similar to that of predicting the El Niño-Southern Oscillation (ENSO) phenomenon (Philander 1990) on interannual time scales. ENSO predictability can also be achieved by using only surface information (e.g., Segschneider et al. 2000; Oberhuber et al. 1998).

Acknowledgments. Thanks to the coupled modeling group at MPI and Prof. Dr. Jens Meincke for fruitful discussions. Dr. J. Gregory performed the HadCM3 experiment. This work was supported by the European Union's PREDICATE, by the German Government's DEKLIM and Ocean-CLIVAR programs, and by the Sonderforschungsbereich 512. The climate simulations were conducted at the German Climate Computer Centre (DKRZ).

\section{REFERENCES}

Bjerknes, J., 1964: Atlantic air-sea interaction. Advances in Geophysics, Vol. 10, Academic Press, 1-82.

Broecker, W. S., D. M. Peteet, and D. Rind, 1985: Does the oceanatmosphere system have more than one stable mode of operation? Nature, 315, 21-26.

Cubasch, U., and Coauthors, 2001: Projections of future climate change. Climate Change 2001: The Scientific Basis, J. T. Houghton et al., Ed., Cambridge University Press, 525-582.

Delworth, T. L., and M. E. Mann, 2000: Observed and simulated multidecadal variability in the Northern Hemisphere. Climate Dyn., 16, 661-676.

_- S. Manabe, and R. J. Stouffer, 1993: Interdecadal variations of the thermohaline circulation in a coupled ocean-atmosphere model. J. Climate, 6, 1993-2011.

Deser, C., and M. L. Blackmon, 1993: Surface climate variations over the North Atlantic during winter: 1900-1989. J. Climate, 6, 1743-1753.

Folland, C. K., D. E. Parker, and F. E. Kates, 1984: Worldwide marine temperature fluctuations 1856-1981. Nature, 310, 670-673.

— - T. N. Palmer, and D. E. Parker, 1986: Sahel rainfall and worldwide sea temperatures. Nature, 320, 602-606.

—_, D. E. Parker, A. W. Colman, and R. Washington, 1999: Large scale modes of ocean surface temperature since the late nineteenth century. Beyond El Niño, A. Navarra, Ed., Springer, 75102.

Giorgetta, M. A., E. Manzini, and E. Roeckner, 2002: Forcing of the quasi-biennial oscillation from a broad spectrum of atmospheric waves. Geophys. Res. Lett., 29, 1245, doi:10.1029/ 2002GL014756.

Gordon, C., C. Cooper, C. Senior, H. Banks, J. M. Gregory, T. C. Johns, J. F. B. Mitchell, and R. Wood, 2000: Simulation of SST, sea ice extents and ocean heat transports in a coupled model without flux adjustments. Climate Dyn., 16, 147-168.

Griffies, S. M., and E. Tziperman, 1995: A linear thermohaline oscillator driven by stochastic atmospheric forcing. J. Climate, $\mathbf{8}$, $2440-2453$.

—_ and K. Bryan, 1997: Ensemble predictability of simulated North Atlantic inter-decadal variability. Science, 275, 181-184.

Grötzner, A., M. Latif, A. Timmermann, and R. Voss, 1999: Interannual to decadal predictability in a coupled ocean-atmosphere general circulation model. J. Climate, 12, 2607-2624.

Hegerl, G., K. Hasselmann, U. Cubasch, J. F. B. Mitchell, E. Roeckner, R. Voss, and J. Waszkewitz, 1997: Multi-fingerprint detection and attribution analysis of greenhouse gas, greenhouse gasplus aerosol and solar forced climate change. Climate Dyn., 13, 613-634.

Hurrell, J. W., 1995: Decadal trends in the North Atlantic Oscillation, regional temperatures and precipitation. Science, 269, 676-679.

Kushnir, Y., 1994: Interdecadal variations in the North Atlantic sea surface temperature and associated atmospheric conditions. $J$. Climate, 7, 141-157.

Latif, M., 1998: Dynamics of interdecadal variability in coupled ocean-atmosphere models. J. Climate, 11, 602-624.

—_, E. Roeckner, U. Mikolajewicz, and R. Voss, 2000: Tropical stabilization of the thermohaline circulation in a greenhouse warming simulation. J. Climate, 13, 1809-1813.

Manabe, S., and R. J. Stouffer, 1988: Two stable equilibria of a coupled ocean-atmosphere model. J. Climate, 1, 841-866.

_ and 1999: The role of thermohaline circulation in climate. Tellus, 51, 91-109.

Marotzke, J., and P. H. Stone, 1995: Atmospheric transports, the thermohaline circulation, and flux adjustments in a simple coupled model. J. Phys. Oceanogr., 25, 1350-1364.

Marsland, S. J., H. Haak, J. H. Jungclaus, M. Latif, and F. Röske, 2003: The Max-Planck-Institute global ocean/sea ice model with orthogonal curvilinear coordinates. Ocean Modell., 5, 91-127.

Oberhuber, J., E. Roeckner, M. Christoph, M. Esch, and M. Latif, 
1998: Predicting the '97 El Niño event with a global climate model. Geophys. Res. Lett., 25, 2273-2276.

Philander, S. G. H., 1990: El Niño, La Niña, and the Southern Oscillation. Academic Press, 293 pp.

Polyakov, I. V., and M. A. Johnson, 2000: Arctic decadal and interdecadal variability. Geophys. Res. Lett., 27, 4097-4100.

Rahmstorf, S., 1999: Shifting seas in the greenhouse? Nature, 399, 523-524.

Saravanan, R., G. Danabasoglu, S. C. Doney, and J. C. McWilliams, 2000: Decadal variability and predictability in the midlatitude ocean-atmosphere system. J. Climate, 13, 1073-1097.

Schiller, A., U. Mikolajewicz, and R. Voss, 1997: The stability of the North Atlantic thermohaline circulation in a coupled oceanatmosphere general circulation model. Climate Dyn., 13, 325 347.

Segschneider, J., D. L. T. Anderson, and T. N. Anderson, 2000: Toward the use of altimetry for operational seasonal forecasting. J. Climate, 13, 3115-3128.
Stommel, H., 1961: Thermohaline convection with two stable regimes of flow. Tellus, 13, 224-230.

Timmermann, A., M. Latif, R. Voss, and A. Groetzner, 1998: Northern Hemisphere interdecadal variability: A coupled air-sea mode. $J$. Climate, 11, 1906-1931.

Visbeck, M., and Coauthors, 1998: Atlantic climate variability experiment prospectus. LDEO Report, $49 \mathrm{pp}$.

- E. P. Chassignet, R. G. Curry, T. L. Delworth, R. R. Dickson, and G. Krahmann, 2003: The ocean's response to North Atlantic Oscillation variability. The North Atlantic Oscillation: Climatic Significance and Environmental Impact, Geophys. Monogr., No. 134, Amer. Geophys. Union, 113-145.

WOCE, 2001: Objective 8-To determine the important processes and balances for the dynamics of the general circulation. US WOCE Implementation Rep. 13, 55 pp.

Wood, R. A., A. B. Keen, J. F. B. Mitchell, and J. M. Gregory, 1999: Changing spatial structure of the thermohaline circulation in response to atmospheric $\mathrm{CO}_{2}$ forcing in a climate model. Nature, 399, 572-575. 